\title{
Laser Structuring of Open Cell Metal Foams for Micro Scale Surface Enlargement
}

\author{
Robert Baumann ${ }^{1, *}$, Thomas Rauscher ${ }^{2}$, Christian Immanuel Bernäcker ${ }^{2}$, Christoph Zwahr ${ }^{1}$, Thomas Werißgärber ${ }^{2}$, Lars \\ Röntzsch ${ }^{2}$ and Andrés Fabián Lasagni ${ }^{1,3}$ \\ ${ }^{1}$ Institute for Manufacturing Technology, Technische Universität Dresden, George-Baehr-Str. 3c, \\ 01069 Dresden, Germany \\ *Corresponding author: robert.baumann1@tu-dresden.de \\ ${ }^{2}$ Fraunhofer Institute for Manufacturing Technology and Advanced Materials IFAM, Branch Lab \\ Dresden, Winterbergstr. 28, 01277 Dresden, Germany \\ ${ }^{3}$ Fraunhofer-Institut für Werkstoff- und Strahltechnik IWS, Winterbergstr. 28, 01277 Dresden, \\ Germany
}

\begin{abstract}
Nowadays, innovative materials have gained an increasing market share in several industrial fields One of these novel materials are open cell metal foams. Those can be found in different industrial applications such as in batteries, implants or chemical filters, since high surface-to-volume ratios are needed. In the past, laser technology highlighted the solution for various challenges concerning the performance improvement of open cell metal foams. The performance of several of these properties can be further improved using laser-based fabrication methods allowing the production of repetitive periodic structures on the micrometer or sub-micrometer scale, such as Direct Laser Interference Pattering (DLIP). In this work, DLIP is utilized for structuring the surface of open cell steel foams. By controlling the laser parameters as well as the geometrical arrangement of the beams, $5.2 \mu \mathrm{m}$ deep structures with a spatial period of $5.8 \mu \mathrm{m}$ were fabricated. The topography of the used materials is characterized using scanning electron microscopy and confocal microscopy. Finally, the surface enlargement of the DLIP-structured foams are electrochemically characterized by determining the double-layer capacitance using cyclic voltammetry $(\mathrm{CV})$ as well as electrochemical impedance spectroscopy (EIS).
\end{abstract}

DOI: $10.2961 /$ jlmn.2020.02.2010

Keywords: open cell metal foam, laser processing, direct laser interference patterning, 316L steel, surface enlargement

\section{Introduction}

Innovative, multifunctional materials have gained exceptional interest for upcoming industrial applications in the field of energy conversion. One of those innovative materials are open cell metal foams. Metal foams are used in a large variety of industrial applications such as current collectors for battery, filters, temperature- and sound shielding or structural elements [1-3].

Over the last decades, several research studies concerning open cell foams were conducted [1-6]. Next to conventional post processing such as milling, grinding and sawing, laser material processing was introduced for innovative solutions concerning joining, shaping and functionalization [6-14]. Especially, the surface functionalization using different laser techniques is a major subject to research interest in the last years.

In this frame, fs-laser systems have been used in the past to increase the performance of flat metallic electrodes in case of the hydrogen evolution reaction (HER), oxygen evolution reaction (OER) as well as for electroorganic synthesis [15-18]. By using fs-laser systems, the surface of nickel electrodes was enlarged by keeping the intrinsic activity towards the HER. Moreover, the HER activity was significantly enhanced in comparison to a smooth, non-structured surface $[15,16]$. In addition, this technique was also used for surface modification of titanium and platinum in order to increase the surface area for electrocatalytic applications [19,21].

Within present laser structuring methods, two major approaches can be identified, including Direct Laser Writing (DLW) which is mainly based on laser ablation and Direct Laser Interference Patterning (DLIP) [26-28]. It is commonly known that the DLIP technique can be used for generating repetitive surface topographies for a huge variety of industrial application. In the last ten years, several examples were presented to achieve super-hydrophobic, anti-icing, wear-resistant or holographic surfaces on different metallic surfaces as well as on polymers and coatings [26-33]. The DLIP uses a coherent pulsed laser beam, which is split into two or even more sub-beams, and are superimposed on the surface of the material. As a result, an interference pattern is achieved at the volume of the overlapping laser beams as illustrated in Fig. 1 [34].

Depending of the angle $\theta$ (see Fig 1 ) on which the two laser beams are overlapped, different spatial periods $(\Lambda)$ can be generated.

In this work, we investigate on the feasibility of laser structuring three dimensional surfaces using the DLIP technique, particularly of open cell metal foams for increasing the component surface. 


\section{Material and methods}

For the experiments, open cell metal foams (Alantum Europe $\mathrm{GmbH}$ ) made from steel 316L (1.4404), were used. The foams have a pore size of $1200 \mu \mathrm{m}$ and a dodecahedronlike cell structure [1]. Due to the manufacturing process, the cell struts have a triangular but hollow cross section with an overall material thickness of $3.2 \mathrm{~mm}$ [6]. For the laser structuring process, a solid-state laser source (Edgewave InnoSlab Nd:YVO4) was utilized which emitted at a wavelength of $1064 \mathrm{~nm}$ with a pulse duration of $10 \mathrm{ps}$ at a repetition rate of $1 \mathrm{kHz}$.

For obtaining the interference patterns, the initial laser beam was split into two sub-beams using a DLIP optical head (Fraunhofer IWS, Dresden), obtaining a line-like surface geometry. This setup enables the possibility to automatically control the angle under which the two sub-beams superimpose on the surface. Note that detailed information about the optical setup has been already published elsewhere [35].

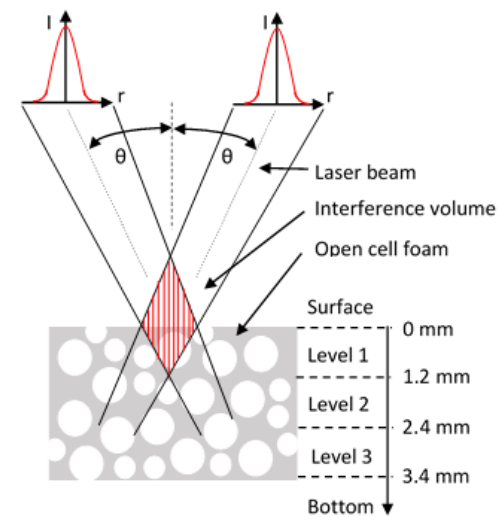

Fig. 1 Schematic representation of the DLIP principle for producing a two-beam interference pattern over the surface of a metallic foam with different depth levels according its three-dimensional morphology. It is worth mentioned that the size of the interference volume is enlarged for better visualization and does not represent the real boundaries.

In consequence, the variation of the interference angle permits to perfectly control the spatial period $(\Lambda)$ according to Equation 1:

$\Lambda=\frac{\lambda}{2 \sin \theta}$

where $\lambda$ is the laser wavelength and $\theta$ is the half angle between the two laser beams (see sketch in Fig 1).

In this study, an interference angle of $\sim 5.2^{\circ}$ was chosen, leading to a spatial period of $\Lambda=5.8 \mu \mathrm{m}$. For the following experiments the DLIP-Pixel diameter was set to $150 \mu \mathrm{m}$. As it is indicated in Fig. 1, using these parameters only this first level of the foam was structured with DLIP fringes due to shadowing effects of the cell struts. Next to the spatial period an important process parameter is the pulse-to-pulse overlap. According to Fig. 2 this parameter describes the amount of overlapping of DLIP-pixels in x- and y-directions. As it can be seen also in Fig. 2, the geometrical distance of the laser spots in the $\mathrm{x}$ and $\mathrm{y}$-axis direction is called "overlap" and "hatch", respectively. For the presented experiments, the

overlap was varied between $86.6 \%$ and $98.6 \%$ at a constant hatch

of

$0 \%$.

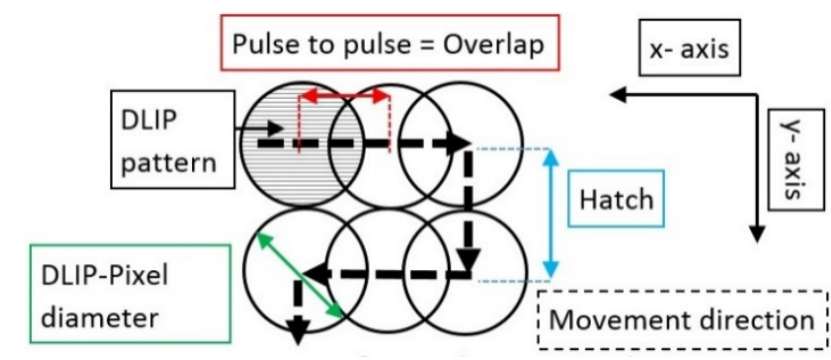

Fig. 2 Sketch of the processing strategy of DLIP and parameter explanation.

In order to characterize the morphology of the laser structures open cell foam, confocal microscopy (Sensofar S Neox) with a magnification objective of $150 \mathrm{x}$ was used. This objective provides a lateral and vertical resolution of $140 \mathrm{~nm}$ and $1 \mathrm{~nm}$, respectively. Topographical analyses in more details were carried out using a scanning electron microscope (ZEISS Supra 40VP) at $5 \mathrm{kV}$ operation voltage.

For determining the electrochemical performance of the treated foams, electrochemical experiments were carried out in 29.9 mass- $\% \mathrm{KOH}$ at $60^{\circ} \mathrm{C}$ in a three-electrode arrangement. The working electrode was placed in a special holder for porous electrodes considering a geometric surface area of $2 \mathrm{~cm}^{2}$ as shown in detail elsewhere [36]. A wrapped platinum wire $\left(\sim 8 \mathrm{~cm}^{2}\right)$ was used as counter electrode. A reversible hydrogen electrode from Gaskatel $\mathrm{GmbH}$ separated through a Haber-Luggin capillary was utilized as reference electrode. Using this configuration, the real surface area of the electrode (foam) can be electrochemically estimated by determination of the double-layer capacitance $\left(\mathrm{C}_{\mathrm{dl}}\right)$ using cyclic voltammetry $(\mathrm{CV})$ as well as electrochemical impedance spectroscopy (EIS).

The double-layer capacitance was estimated from cyclic voltammograms with variating scan rates from 1 to $0.02 \mathrm{~V} / \mathrm{s}$. Furthermore, impedance spectra were recorded subsequently with a delay of $60 \mathrm{~s}$. EIS measurements were performed in a frequency range between $40 \mathrm{kHz}$ and $0.03 \mathrm{~Hz}$ with an amplitude of $5 \mathrm{mV}$. The complex nonlinear leastsquares (CNLS) fitting routine of the software "Gamry Echem Analyst" (Gamry Instruments) was used for data analysis. More details on this method have been already published elsewhere [36-38]

\section{Results and discussion}

By superimposing two coherent laser beams, a line-like pattern is generated at the volume where the two laser beams overlap. In consequence, the utilization of the DLIP technique for structuring three-dimensional foam structures is very promising, since the periodic structures are created in a large volume and the resolution of the periodic features only depends on the shape of the interference pattern.

Exemplary SEM images of a DLIP treated steel foam shown in Fig. 3 (with $98.6 \%$ overlap and $3.3 \mathrm{~J} / \mathrm{cm}^{2}$ of laser fluence and a spatial period of $5.8 \mu \mathrm{m}$ ) reveal that these complex geometries can be successfully treated using this method. 

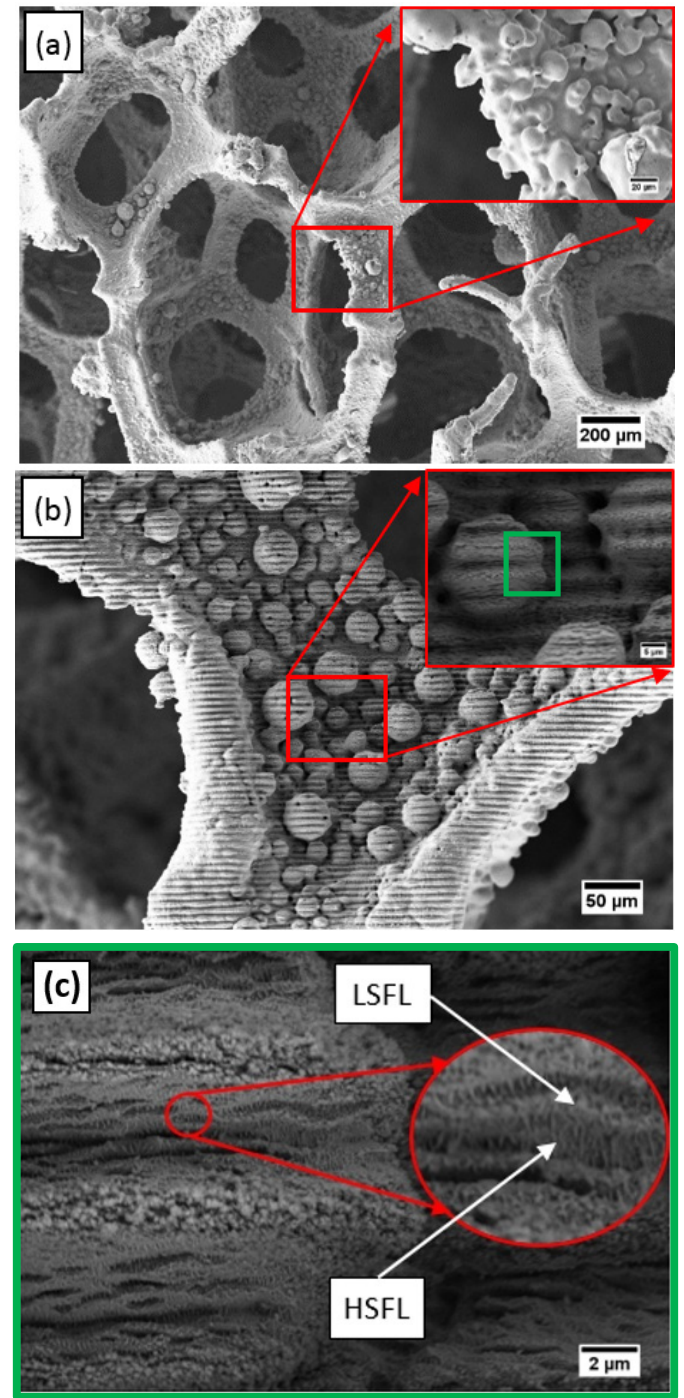

Fig. 3 SEM images of untreated open cell foam out of steel (a) as well as with line-like pattern produced using DLIP (b). The insets in (a) and (b) show a magnification of the highlighted area for better visualization; magnification of the green highlighted section of the inset for better visualization of high (HSFL) and low (LSFL) spatial frequency LIPSS (c); overlap: $98.6 \%$; fluence: $3.34 \mathrm{~J} / \mathrm{cm}^{2}$; spatial period: $5.8 \mu \mathrm{m}$.

In comparison, the non-laser treated reference is illustrated in Fig. 3a. The surface pattern produced by the laser intensity modulation is detectable also at the non-planar regions of the steel foam, even atop the particle-like features which results from the manufacturing process for increasing the corrosion resistance. The particles originate from the manufacturing process of the metal foam (see Fig. 3b) [39]. Both SEM images showed in Fig. 3 were taken at "Level 1" of the foam according to the sketch in Fig. 1.

The pulse-to-pulse overlap and the laser fluence were raised to the maximum value of $98.6 \%$ and $3.34 \mathrm{~J} / \mathrm{cm}^{2}$, respectively. As shown in previous studies, additional surface pattern, known as laser induces periodic surface structures (LIPSS) decorate the line-like geometries produced by DLIP, if ultra-short pulsed laser radiation interacts with the metallic surfaces [19-21,24,40-42]. These additional periodic pattern can be detected inside the DLIP fringes, as shown in Fig. 3c. In consequence, next to the DLIP fringes, these LIPSS features create a periodic nano-roughness leading to a further favorable increase of the overall surface area [33].

According to Fig. 3c, two different types of LIPSS were produced within the DLIP features, described as low and high spatial frequency LIPSS (LSFL and HSFL, respectively). The LSFL are oriented parallel to the DLIP structures since the used polarization of the laser beams was also oriented following the direction of the line-like geometry [34]. It is worth mentioned that the size (spatial period) of the DLIP fringes, which can be calculated according to Eq. 1, does not influences the size of the LIPSS. The size of the LSFL was $\sim 810 \mathrm{~nm}$, which is similar to the used laser wavelength, which is typical for these structures. Differently, the HSFL were oriented perpendicular to the DLIP features with a spatial period of $\sim 130 \mathrm{~nm}$, which is much smaller than the used laser wavelength and is also characteristic for this kind of structures on steel surfaces [35]. Here, as in most cases, the HSFL were oriented parallel to the laser beam polarization and thus are perpendicular to the LSFL. A detailed description of the origin, generation and orientation of LSFL and HSFL can be found elsewhere $[26,43]$.

The results presented in the previous section correspond to the structures produced on top of the metallic foam, at "Level 1" according to Fig. 1. However, the improvement of the performance of the metallic foams required also to structure the surface at different levels. In consequence, additional analysis of the surface morphology of the metallic foam were performed. As it was shown in Figs. 3b and c, the DLIP structure were successfully produced within the first level of the foam, as well as HSFL and LSFL structures. With increasing foam level, which is represented by a certain depth into the structure, only LIPSS were detectable. For example, for the used spatial period of $5.8 \mu \mathrm{m}$ only LIPSS (HSFL and LSFL) were detected up to level 4, corresponding to a thickness of $3.2 \mathrm{~mm}$ from the top of the foam.

After the previously presented qualitative analyses regarding the formation of DLIP, LSFL and HSFL structures, for increasing the structure depth of the DLIP pattern, the influence of overlap and the fluence was investigated. The results are presented in Fig. 4. As it can be seen in the figure, the pulse-to-pulse overlap was raised from $86.6 \%$ up to $98.6 \%$. Values below $86.6 \%$ depicted in preliminary experiments have shown no detectable surface structure and consequently those values where not further investigated in this study. Next to the pulse-to-pulse overlap, the laser fluence was increased from $1.13 \mathrm{~J} / \mathrm{cm}^{2}$ up to $3.34 \mathrm{~J} / \mathrm{cm}^{2}$. For examining the results, confocal microscopy and software were applied in order to evaluate the mean structure depth. 


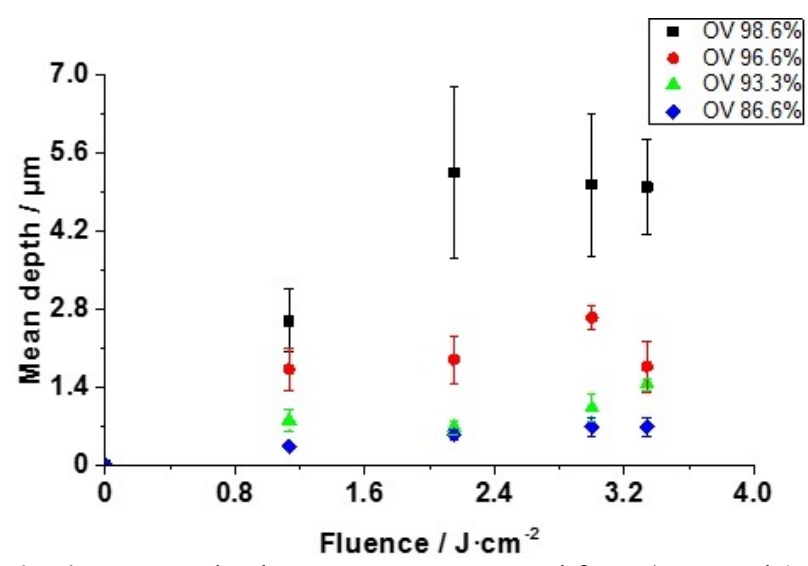

Fig. 4 Structure depth measurements on steel foam (at "Level 1") in dependence of the overlap and laser fluence, measured using confocal microscopy. The spatial period of the DLIP structure was $5.8 \mu \mathrm{m}$.

As it can be seen in Fig. 4, with increasing overlap the mean depth of the DLIP pattern, for nearly all samples, also increased. The highest depth values were measured for the largest overlap of $98.6 \%$, independently of the used laser fluence. Mean depths of $\sim 5 \mu \mathrm{m}$ were reached, which represents an aspect ratio of nearly one. In contrast, with an overlap value of $96.6 \%$, the maximum mean depth was $2.3 \mu \mathrm{m}$. This trend reveals that the pulse-to-pulse overlap depicts the largest impact on the created mean structure depth in the investigated range of laser fluence. However, the deviation of the results become larger as well, especially for the highest overlap of $98.6 \%$.

Finally, the surface area of the DLIP treated foam was electrochemically determined in comparison to an unstructured steel foam.

For the electrochemical analysis, a structured foam with a spatial period of $5.8 \mu \mathrm{m}$ and a structure depth of $5.0 \mu \mathrm{m}$ at "Layer 1" was used (referred to as DLIP_1). This steel foam was produced using an overlap of $98.6 \%$ and a fluence of $3.3 \mathrm{~J} / \mathrm{cm}^{2}$ as described before. The surface area of electrodes was determined by measuring the double-layer capacitance [38]. Therefore, a potential region was applied, where no significant Faradaic reactions occur and the net current can mostly be attributed to the charging of the double-layer capacitance. This potential region was evaluated by a cyclic voltammogram as shown in Fig. 5. For the DLIP-structured as well as for the unstructured foam similar cyclic voltammograms are recorded, which suggest that the redox-behavior is not affected by the DLIP structuring process. Exemplarily, for both samples a peak at $1.41 \mathrm{~V}$, prior to the oxygen evolution reaction can be found. This peak can be attributed to the $\mathrm{Ni}(\mathrm{OH})_{2} / \mathrm{NiOOH}$-transition [39]. Note that $\mathrm{Fe}$ as well as $\mathrm{Cr}$ show also electrochemical features in this potential region [44]. Furthermore, a potential region can be found, where no significant Faradaic reactions are expected as shown in Fig. 6b.

Accordingly, the surface area was determined in this potential region by two electrochemical methods: (i) cyclic voltammetry with variating scan rate and (ii) electrochemical impedance spectroscopy.

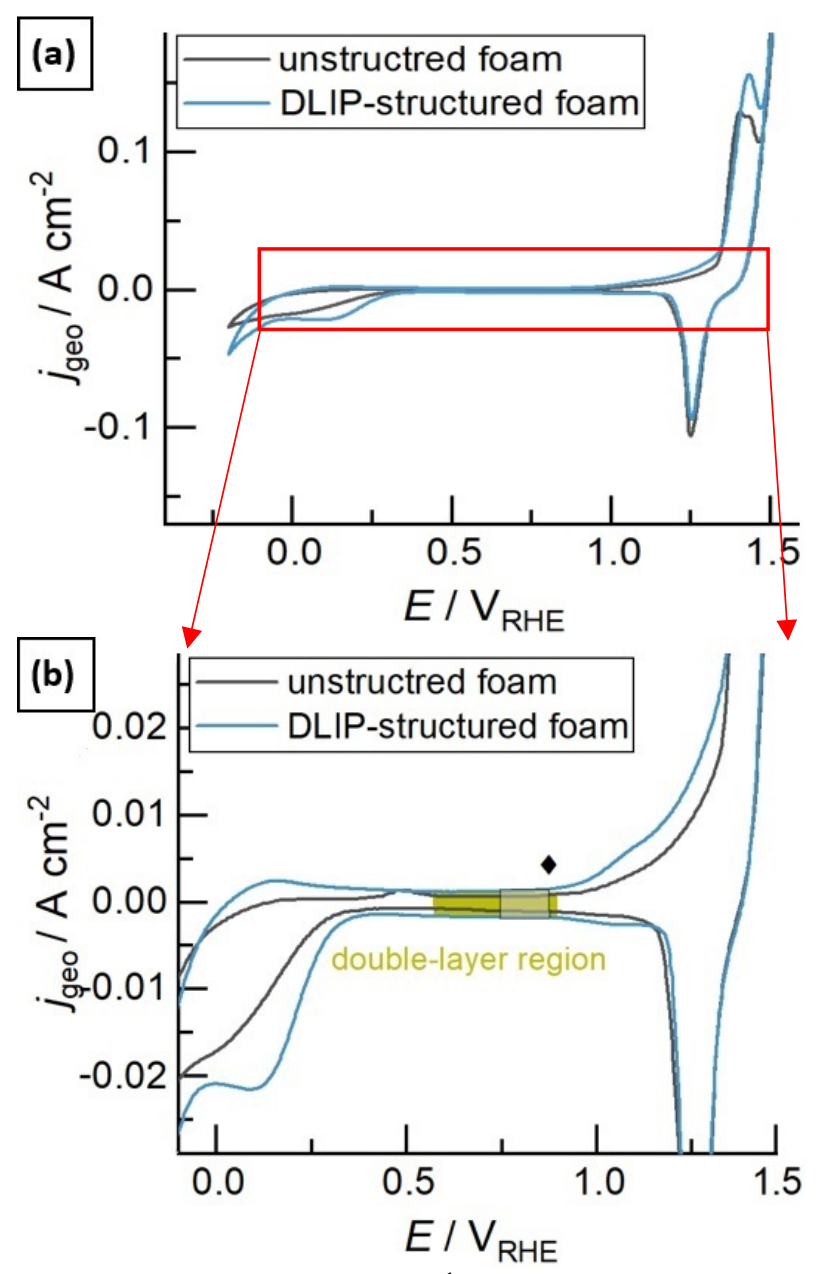

Fig. 5 Cyclic voltammogram $\left(2^{\text {nd }}\right.$ cycle $)$ of unstructured and DLIP-structured steel foam (DLIP_1) in a $\mathrm{N}_{2}$-purged 29.9 mass- $\% \mathrm{KOH}$ at $60^{\circ} \mathrm{C}$ (a). Enlarged section to show the potential region where no significant Faradaic reactions can be expected (marked with $\$)(b)$.

The cyclic voltammograms recorded with varying scan rates for unstructured and DLIP structured foam are illustrated in Figs. 6a and 6b. For both electrodes, nearly rectangular cyclic voltammograms were recorded, suggesting that no significant Faradaic reactions occur and a suitable potential window for determining the double-layer capacitance was found. Accordingly, the double-layer capacitance was calculated by plotting the average of the absolute anodic $\left(j_{\mathrm{a}}\right)$ and cathodic current $\left(j_{\mathrm{c}}\right)$ densities against the scan rate $(v)$ [39, 45-46] (see Fig. 7c) according to following equation:

$$
C_{d l}=\frac{j_{a}+\left|j_{c}\right|}{2 \cdot v}
$$

The determined capacitance of the unstructured foam is around $702 \mu \mathrm{Fcm}^{-2}$. For the DLIP structured foam a capacitance of $1330 \mu \mathrm{Fcm}^{-2}$ was measured, which is about 2 times higher compared to the unstructured foam. 

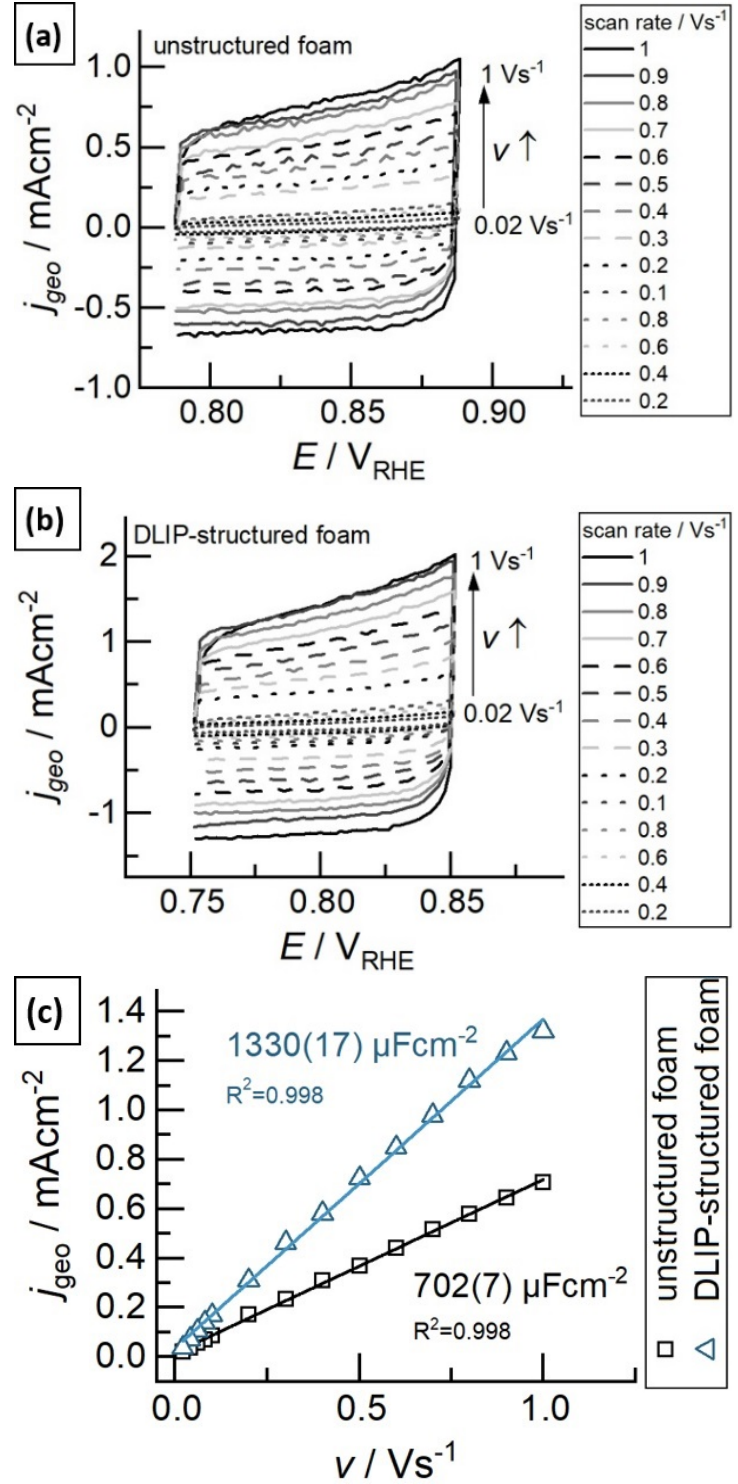

Fig. 6 Capacitance measurements for determining surface area on unstructured and DLIP-structured foam in a $\mathrm{N}_{2}$-purged

29.9 mass- $\% \mathrm{KOH}$ at $60^{\circ} \mathrm{C}$. Cyclic voltammograms with variating scan rate of unstructured (a) and DLIP-structured steel foam (b). The average of the absolute anodic and cathodic current densities versus the scan rate (c). The capacitance is determined by the slope of the linear fits to the data. All currents are assumed to be due to capacitive charging.

In addition, the double-layer capacitance was measured by impedance measurements (EIS) as a complementary method. Fig. 7 shows the Nyquist representation of the impedance data of the unstructured and structured foam. In both cases, a depressed semi-circle can be seen which can be attributed to porosity or surface roughness of the electrode [47]. Accordingly, the data were approximated by the modified Randles circuit shown in Fig. 7, whereas the capacitance is replaced by a constant phase element. It is assumed that the double-layer capacitance can be calculated by the following equation [47]:

$C_{d l}=\left[Y\left(R_{S}^{-1}+R_{C t}^{-1}\right)^{(\alpha-1)}\right]^{\frac{1}{\alpha}}$

where $Y$ is the parameter of the constant phase element, $\alpha$ is related to the phase angle of the frequency response, $R_{S}$ is the solution resistance and $R_{c t}$ is the charge transfer resistance. The CPE (constant phase element) instead of a real capacitance was used because a depressed semi-circle is observed. Additionally, a resistance was added in serial because the circle cuts the $\mathrm{x}$-axis at values greater than zero. In summary, no indication of the use of an inductor is seen. Thus, the simple equivalent circuit model was used. This is in accordance to previous works $[15,37]$. The parameters obtained from the EIS measurement are shown in Table 1. For both electrodes the constant phase angle parameter, $\alpha$, is nearly 0.9 . Note, for $\alpha=1$ the CPE reflects an ideal capacitance [47]. Furthermore, the increase of the parameter of the constant phase element, $Y$, and the decrease of the charge transfer resistance, $R_{\mathrm{S}}$, of the DLIP structured foam compared to the unstructured foam are mainly caused by the enhancement of the active surface area because these values are calculated by considering the geometric surface area, but depending on the real surface area.

In Table 2, the double-layer capacitances determined by both methods are summarized. The difference between both methods is about $35 \%$ which is slightly higher than the range of permitted deviation ( \pm 15 to $30 \%$ ) $[19,36]$. Nevertheless, the value is in the same order of magnitude. These differences can be explained by a further possible contribution of the measured capacitance, for example, pseudo-capacitances. In principle, the capacitance value should be considered as an approximate value for the real surface area.

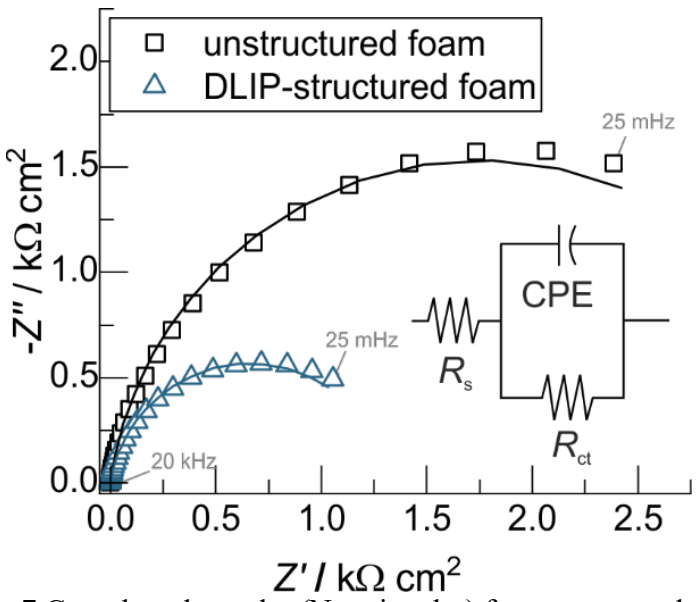

Fig. 7 Complex plane plot (Nyquist plot) for unstructured and DLIP structured foam in a $\mathrm{N}_{2}$-purged 29.9 mass- $\% \mathrm{KOH}$ solution at $60^{\circ} \mathrm{C}$. Symbols are experimental points and solid lines are fits by the Randles CPE model.

Table 1 Parameters obtained from the EIS measurements. The data were fitted with the Randles CPE model (CPE instead of a real capacitance, see insert in Fig. 7). The errors include the uncertainty of the fitted parameters.

\begin{tabular}{lcccc}
\hline Sample & $\begin{array}{c}R_{\mathrm{S}} / \Omega \\
\mathrm{cm}^{2}\end{array}$ & $\begin{array}{c}R_{\mathrm{P}} / \Omega \\
\mathrm{cm}^{2}\end{array}$ & $\begin{array}{c}Y / \mu \mathrm{S} \mathrm{s} \\
\mathrm{cm}^{-2}\end{array}$ & $a /-$ \\
\hline $\begin{array}{l}\text { Unstruc- } \\
\text { tured foam }\end{array}$ & $0.21 \pm 0.01$ & $3515 \pm 59$ & $974 \pm 7$ & $0.91 \pm 0.01$ \\
DLIP_1 & $0.27 \pm 0.01$ & $1320 \pm 20$ & $1907 \pm 13$ & $0.90 \pm 0.01$ \\
\hline
\end{tabular}


Table 2 Estimated capacitance by CV and EIS measurements.

\begin{tabular}{lcc}
\hline \multirow{2}{*}{ Sample } & \multicolumn{2}{c}{ Capacitance, $C / \mu \mathrm{F} \mathrm{cm}^{-2}$} \\
& $\mathrm{CV}$ & $\mathrm{EIS}$ \\
\hline Unstructured foam & $702 \pm 7$ & $430 \pm 5$ \\
DLIP_1 & $1330 \pm 17$ & $852 \pm 12$ \\
\hline
\end{tabular}

Based on the measured double-layer capacitance, the DLIP structuring of the metallic porous foam leads to an enlargement of the surface area by approximately a factor of 2 (1.89 and 1.98 according to capacitance determined by $\mathrm{CV}$ and EIS, respectively). Gabler et al. generated LIPSS on a smooth Ni surface by using a femtosecond laser pulse technique with a surface enlargement of 3 compared to a smooth sample [20]. This value is similar to the determined surface enlargement factor of the DLIP-structured porous metallic foam. As a consequence, it can tentatively be concluded that also deeper structures of the foam can be textured using the DLIP technique which is in agreement with microscopic observations. Furthermore, it has to be taken into account that covered or inaccessible surface areas of the 3D foam material is not structured using the DLIP process and different surface features are generated depending on the different depths levels (see Fig. 1). Accordingly, the differences in the surface enlargement factors are expected if a planar or a 3D porous substrate is laser structured. In addition, it has to be mentioned that the here reported results were obtained in an already improved material due to the 3D geometry of the foam, which has an already high surface area. In consequence, the obtained results are very promising for improving the electrochemical performance of metallic electrodes.

\section{Conclusion}

According to our knowledge, for the first time open cell metal foams were textured using the DLIP technique. By using a picosecond pulse laser source with a wavelength of $1064 \mathrm{~nm}$, a pattern with a spatial period of $5.8 \mu \mathrm{m}$ was fabricated. Structure depths up to $5 \mu \mathrm{m}$ were achieved, which represents an aspect ratio of nearly 1 . Next to the interference fringes at the first level of the foam, LIPSS (LSFL and HSFL) could be detected through all depth levels of the foam. The size of the LSFL and HSFL were $810 \mathrm{~nm}$ and $130 \mathrm{~nm}$, respectively. Moreover, electrochemical characterizations were performed to determine the electrochemically accessible surface area using cyclic voltammetry (CV) and electrochemical impedance spectroscopy (EIS). The investigations revealed an increase of capacitance from $702 \mu \mathrm{F} \mathrm{cm}{ }^{-2}$ for unstructured foam to $1330 \mu \mathrm{F} \mathrm{cm}$-2 for DLIP enhanced foam, which represents a surface enlargement factor of almost 2 . It has to be mentioned that for a material that already has a high surface area-to-volume ratio, a further increase in surface area (by almost a factor of two) represents a significant improvement in terms of potential industrial applications such as hydrogen generation. In the future, research will be conducted in order to increase the overall structured area further.

\section{Acknowledgments}

The work of R. B. has received funding from the European Union's Horizon 2020 research and innovation program under Grant Agreement No. 825132. It is an initiative of the Photonics Public Private Partnership. (www.photonics21.org). The work of A. F. L. was also supported by the
German Research Foundation (DFG) under Excellence Initiative program by the German federal and state governments to promote top-level research at German universities. Further, the work was supported by the Federal Ministry for Economic Affairs and Energy (BMWi) of the Federal Republic of Germany (support code: 03ET6063A).

\section{References}

[1] M.F. Ashby, A.G. Evans, N.A. Fleck, L.J. Gibson, J.W. Hutchinson, and H.N.G. Wadley: "Metal Foams: A Design Guide"; (Butterwoth-Heinemann,Bosten, 2000) 212.

[2] J. Bahnhart: Adv. Eng. Mater., 2, (2000) 188.

[3] C. Koerner and R.F. Singer: Adv. Eng. Mater., 2, (2000) 159.

[4] H. Nakajima: Prog. in Mat. Sci., 52, (2007) 1091.

[5] F. Quadrini, A. Guglielmotti, E.A. Squeo, and V. Tagliaferri: J. of Mat. Pro. Tech., 210, (2010) 1517.

[6] R. Baumann, P. Herwig, A. Wetzig, and E. Beyer: Adv. Eng. Mater., 19, (2017) 170.

[7] M. Bram, C. Kempmann, A. Laptev, D. Stöver, and K. Weinert: Adv. Eng. Mater., 5, (2003) 441.

[8] K. Weinert, M. Bram, C. Kempmann, and D. Stoever: Prod. Eng., 10, (2003) 65.

[9] Y. Matsumoto, A.H. Brothers, S.R. Stock, and D.C. Dunand: Mat. Sci. and Eng.: A, 447, (2007) 150.

[10]E. Muñoz, M.de Val, M.L. Ruiz-González, C. LópezGascón, M.L. Sanjuán, M. Teresa Martínez, J.M. González-Calbet, G.F. de La Fuente, and M. Laguna: Chem. Phys. Lett., 420, (2006) 86.

[11]H. Riegel, M. Merkel and A. Öchsner: Mat.-wiss. u. Werkstofftech., 43, (2012) 441.

[12] B.S. Yilbas, S.S. Akhtar and O. Keles: Opt. Laser Technol., 48, (2013) 523.

[13]B.S. Yilbas, S.S. Akhtar and O. Keles: Opt. Lasers Eng., 51, (2013) 23.

[14]B.S. Yilbas, S.S. Akhtar and O. Keles: Int. J. Adv. Manuf. Technol., 79, (2015) 101.

[15]T. Rauscher, C.I. Müller, A. Gabler, T. Gimpel, M. Köhring, B. Kieback, W. Schade, and L. Röntzsch: Electro. Acta, 247, (2017) 1130.

[16]A. Gabler, C.I. Müller, T. Rauscher, M. Köhring, B. Kieback, L. Röntzsch, and W. Schade: Int. J. Hydrogen Energy, 42, (2017) 826.

[17]F. Rieck genannt Best, J. Koch, G. Lilienkamp, F. Körkemeyer, H. J. Maier, J. Caro, and K. Lange: Int. J. Electrochemistry, 1, (2018) 1.

[18] M. Koj, T. Gimpel, W. Schade, and T. Turek: Int. J. Hydrogen Energy, 44, (2019) 12671.

[19]S. Waldvogel, S. Beil, T. Müller, S. Sillart, P. Franzmann, A. Bomm, M. Holtkamp, U. Karst, and W. Schade: Angew. Chem. Int. Ed., (2018) 2450.

[20]K. Lange, M. Schulz-Ruhtenberg and J. Caro: ChemElectroChem, (2016) 570.

[21] A. Gabler, C.I. Müller, T. Rauscher, T. Gimpel, R. Hahn, M. Köhring, B. Kieback, L. Röntzsch, and W. Schade: Int. J. Hydrogen Energy, 43, (2018) 7216.

[22]S. Indrisiunas, B. Voisiat, A. Žukauskas, and G. Račiukaitis: Proc. SPIE, Vol. 9350, (2015) 935003.

[23] J. Castellanos, S. Betancourt-Pagan, E. Robledo-Ortiz, L. Pacheco-Londoño, M. De Jesús, and S. HernándezRivera: J. Laser Micro/Nanoengin., 10, (2015) 263. 
[24] J. Chen, J.P. Ulerich, E. Abelev, A. Fasasi, C.B. Arnold, and W.O. Soboyejo: Mat. Sci. Eng. C, 29, (2009) 1442.

[25]J.T. Cardoso, A.I. Aguilar-Morales, S. Alamri, D. Huerta-Murillo, F. Cordovilla, A.F. Lasagni, and J.L. Ocaña: Opt. Lasers Eng, 111, (2018) 193.

[26]A.Y. Vorobyev and C. Guo: Laser \& Photonics Reviews, 7, (2013) 385.

[27]B. Raillard, J. Rémond, E. Ramos-Moore, N. Souza, C. Gachot, and F. Mücklich: Adv. Eng. Mater., 15, (2013) 341.

[28] A.F. Lasagni, T. Kunze, M. Bieda, D. Günther, A. Gärtner, V. Lang, A. Rank, and T. Roch: Proc. SPIE, Vol. 9735, (2016) 973515.

[29] A.F. Lasagni, A.I. Aguilar Morales, C. Zwahr, F. Rößler, S. Alamri, V. Lang, and T. Kunze: Proc. LPM 2017, (2017) A206.

[30]A.F. Lasagni, S. Alamri, A.I. Aguilar-Morales, F. Rößler, B. Voisiat, and T. Kunze: Appl. Sci., 8, (2018) 1260.

[31]A. Rosenkranz, M. Hans, C. Gachot, A. Thome, S. Bonk, and F. Mücklich: Lubricants, 4, (2016) 2.

[32]A. Mousavi, T. Sperk, T. Gietzelt, T. Kunze, A.F. Lasagni, and A. Brosius: KEM, 767, (2018) 77.

[33]S. Milles, B. Voisiat, M. Nitschke, and A.F. Lasagni: J. of Mat. Proc. Technol., 270, (2019) 142.

[34] A.F. Lasagni: Adv. Opt. Technol., 6, (2017) 265.

[35] A.I. Aguilar-Morales, S. Alamri, T. Kunze, and A.F. Lasagni: Opt. Laser Technol., 107, (2018) 216.

[36] C.I. Bernäcker, T. Rauscher, T. Büttner, B. Kieback, and L. Röntzsch: J Elec.chem. Soc., 166, (2019) 357.

[37] C.C.L. McCrory, S. Jung, J.C. Peters, and T.F. Jaramillo: J. Am. Chem. Soc., 135, (2013) 77.

[38] S. Trasatti, O.A. Petrii: Pure and Appl. Chem., 63, (1991) 11

[39] G. Walther, B. Klöden, T. Büttner, T. Weissgärber, B. Kieback, A. Böhm, D. Naumann, S. Saberi, and L. Timberg: Adv. Eng. Mater., 10, (2008) 803.

[40]A. Kietzig, S. Hatzikiriakos and P. Englezos: J. Appl. Phys., 106, (2009) 0243031.

[41] J. Bonse, J. Krüger, S. Höhm, and A. Rosenfeld: J. Laser Appl., 24, (2012) 1.

[42]J. Wang and C. Guo: J. Appl. Phys., 100, (2006) 1.

[43] J. Bonse, S. Hohm, S.Kirner, A. Rosenfeld, and J.Kruger: IEEE J. Select. Topics Quantum Electron., 23, (2017) 75 .

[44]F. Moureaux, P. Stevens, G. Toussaint, and M. Chatenet: J. Pow. Sour., 229, (2013) 123.

[45]E. Gileadi: "Physical Electrochemistry: Fundamentals, Techniques and Applications", (Wiley-VCH, Weinheim, 2011) 113.

[46]C.H. Hamann and W. Vielstich: „Elektrochemie“, (Wiley-VCH, Weinheim, 2005) 71.

[47] M.E. Orazem and B. Tribollet: "Electrochemical Impedance Spectroscopy", (Wiley, Weinheim, 2008) 233.

(Received: June 10, 2020, Accepted: September 7, 2020) 